\title{
SERUM STUDIES ON THE ETIOLOGY OF INFLUENZA
}

John A. Kolmer, Mary E. Trist, and Elizabeth Yagle

From the Pathological Laboratories of the Graduate School of Medicine of the Universioy of Pennsylvania and the Philadelphia Hospital for Contagious Diseases

Until the recent pandemic, the bacillus of influenza was quite generally accepted as the cause of this disease, although the evidence never has been conclusive. The investigations of Wollstein ${ }^{1}$ and Davis $^{2}$ have shown that bacilli resembling the influenza bacillus are found in the upper respiratory tract of persons suffering not only from influenza but from other diseases, so that these bacilli may be considered as widely distributed. At the present time much confusion exists in the results of bacteriologic examinations of the secretions and lesions of the respiratory tract of persons suffering and succumbing to influenza and owing to the difficulties encountered in the isolation of $\mathrm{B}$. influenzae until considerable experience has been gained, such discrepancies in results are to be expected. Many regard the disease as due to $B$. influenza with streptococci, pneumococci, M. catarrhalis and staphylococci as organisms of secondary infection, one or more assuming importance according to their geographical distribution. However, opinion is steadily gaining to the effect that the cause of influenza has not been discovered and that the influenza bacillus is to be classed with the secondary organisms but probably occupying chief place among them and capable of producing bronchitis and bronchopneumonia either alone or in conjunction with streptococci, pneumococci, M. catarrhalis, staphylococci and B. mucosus.

Opinions regarding the relationship of these various bacteria to influenza have been based mainly on bacteriologic examinations of the sputum of persons suffering with influenza and to a lesser extent on examination of the bronchi and lungs of fatal cases; owing to the wide distribution of streptococci, pneumococci (particularly type 4), M. catarrhalis, staphylococci and bacilli similar to the influenza bacillus in the mouth and upper air passages of most persons irrespective of

Received for publication Feb. 8, 1919.

1 Jour. Exper. Med., 1906, 8, p. 681.

2 Jour. Infect. Dis., 1907, 4, p. 73. 
influenza, the exact rôle they exert in the infection is difficult to evaluate. For this reason we have made certain serum studies in influenza for the purpose of determining whether or not antibodies were produced by these various organisms (excepting pneumococci) with the hope that the results under limitations mentioned later, would throw additional light on the etiology of the disease.

Little is known of the immunity response to the influenza bacillus except that agglutinins appear in the blood rather tardily; Wollstein ${ }^{1}$ found agglutinin in the serum of two cases of influenza after the 8th day of the disease, but further investigations do not appear to have been made.

Our main purpose was to determine whether antibodies for B. influenzae occur normally in the serum and the degree and kind of antibody production for this bacillus during influenza. Similar studies were made with streptococci, M. catarrhalis, staphylococci and other organisms isolated from persons suffering from or succumbing to influenza, on the basis that such immunological examinations may show in a broad and general manner which of these organisms had assumed sufficient pathogenicity in Philadelphia to stimulate antibody production.

The serums of 9 healthy adults varying in age from 20-32 years, who had escaped influenza and had not received any vaccine, and the serums of 31 adults in varying stages of influenza were tested for the presence of thermostabile opsonin, agglutinin and complement fixing antibody with various bacterial antigens; comparison is made of the results obtained with serums of healthy persons and with those obtained in varying stages of influenza inasmuch as opportunity was not afforded for the examination of the serums of persons prior to their illness or at intervals during the attack of the disease.

\section{ANTIGENS}

All of the antigens were polyvalent, prepared of a varying number of cultures of the respective organisms freshly isolated from the secretions and lesions of the upper respiratory tract of persons from the 4th to the 9th day of the disease, as follows:

1. Streptococcus antigen was prepared of cultures of freshly isolated hemolytic streptococci from 8 persons.

2. Catarrhalis antigen was prepared of cultures of freshly isolated micrococci from 7 persons. 
3. Staphylococcus antigen was prepared of cultures of Staph. aureus from 16 persons.

4. Pseudodiphtheria antigen was prepared of cultures from 6 persons.

5. Influenza antigen was prepared of cultures of gram-negative, nonmotile, nonspore forming, pleomorphic and absolute hemophilic bacilli from 4 different persons.

6. Wassermann reactions were made with each serum, using for antigen an alcoholic extract of beef heart reentorced with cholesterin.

\section{RESULTS OF COMPLEMENT FIXATION}

All of the antigens were prepared by suspending the various bacteria in normal salt solution followed by heating at $60 \mathrm{C}$. for 1 hour and titration for anticomplementary activity. In the fixation tests each antigen was employed in a dose equivalent to one-third the anticomplementary unit.

The antigenic activity of all antigens was highest when freshly prepared; antigens preserved in a refrigerator for 4 weeks had lost antigenic sensitiveness to a marked degree.

All serums were heated at $56 \mathrm{C}$. for one-half hour and used in a dose of $0.2 \mathrm{cc}$.

An antisheep hemolytic system was employed and all tests were conducted in duplicate, one set being incubated for 1 hour in a waterbath at $38 \mathrm{C}$. and the second in a refrigerator at 5-12 C. for at least 12 hours prior to the addition of hemolysin and indicator antigen.

In all experiments the usual controls were included and the results read and recorded immediately after the second period of incubation and complete hemolysis of the controls.

\section{RESULTS WITH SERUMS OF HEALTHY PERSONS}

The results with the serum of 9 Wassermann negative and healthy adults who had never had influenza insofar as they knew and 2 of whom contracted the disease subsequent to these tests were all wholly negative and indicate the absence of complement fixing for the antigens employed; particular interest was paid the antigen of B. influenzæ. 
RESULTS WITH SERUMS OF PERSONS SUFFERING WITH INFLUENZA

The results of complement fixation tests with the serums of 31 persons in the various stages of acute influenza are shown in tables 1 and 2.

As far as could be ascertained, all of these persons were suffering with a primary attack of the disease.

The word "none" under complications as listed in the tables is used in a purely clinical sense and indicates that at the time blood was drawn for these tests the attending physicians could not detect signs of pneumonia or other complications; the term "pneumonia" refers to the bronchopneumonia of special characteristics so prevalent during this pandemic.

The earliest test was on the 3rd day after the onset of symptoms and the last 5 weeks after the onset.

The results may be summarized as follows:

With the polyvalent antigen of $\mathrm{B}$. influenzæ positive reactions resulted with 16 serums $(51 \%)$ in the water-bath series and with 14 serums $(45 \%)$ in the refrigerator series. The earliest positive reaction observed occurred on the 4th day of the disease.

With the polyvalent antigens of hemolytic streptococci and Micrococcus catarrhalis positive reactions resulted with about $38 \%$ of serums with each antigen.

With the polyvalent antigens of staphylococcus and pseudodiphtheria bacillus the reactions were generally negative. One patient on the 15th day of the disease yielded a weakly positive reaction with the staphylococcus antigen.

\section{RESULTS OF PHAGOCYTOSIS TESTS}

In these experiments the various bacterial emulsions were polyvalent and prepared by suspending the respective organisms in normal salt solution in proper density and free of clumps. Freshly prepared washed human leukocytes from healthy laboratory assistants were employed; all serums were heated at $56 \mathrm{C}$. for half an hour prior to the tests which were made in capillary pipets after the method of Wright and incubated for half an hour when duplicate smears were prepared.

In order to reduce the degree of error consequent to variation in the leukocytes and cultures, all serums were carefully preserved after 

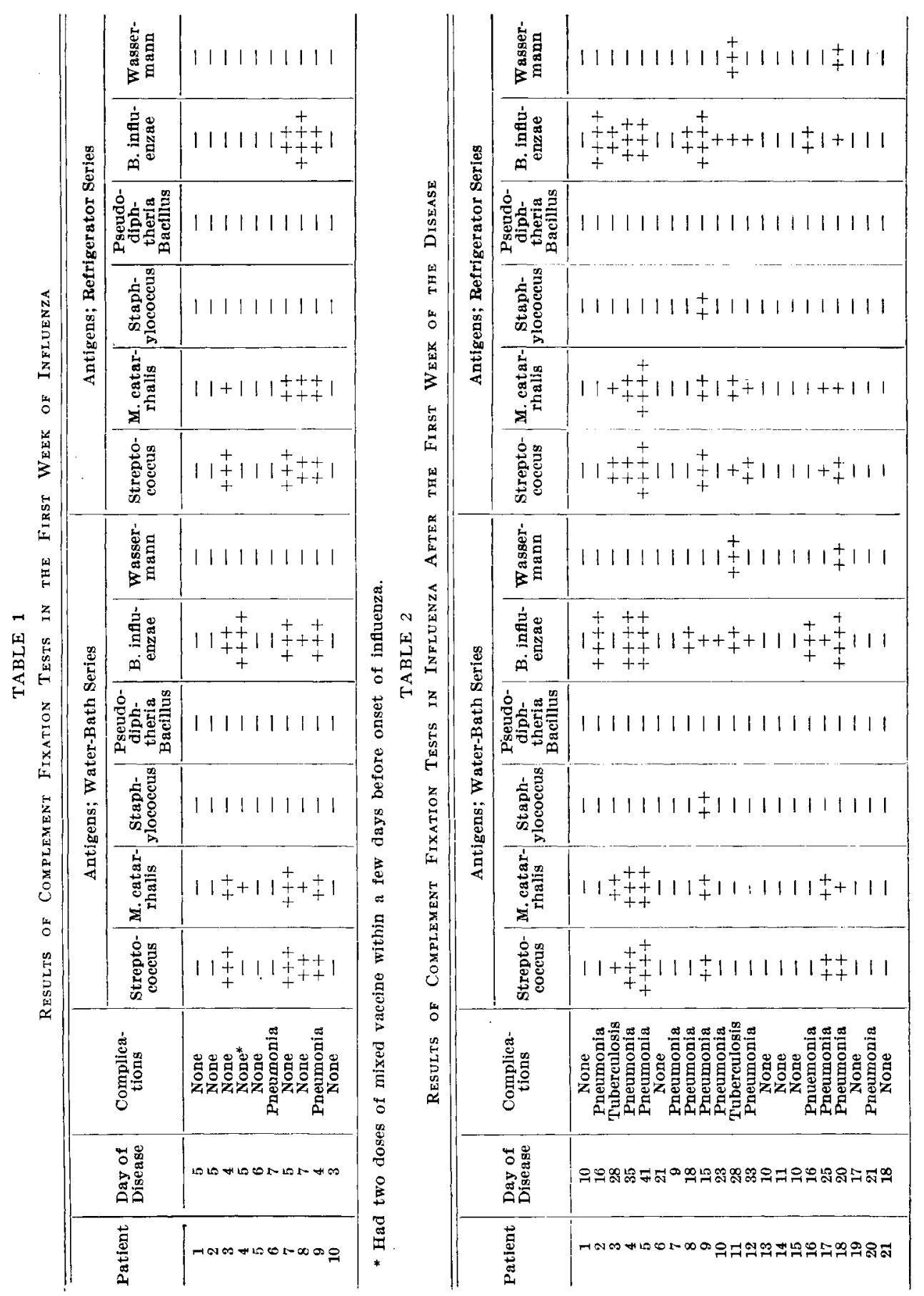
collection and the phagocytosis tests conducted with heated serums for thermostabile opsonins (at the same time) so that the results would be strictly comparable.

In the smears from 50-100 polymorphonuclear leukocytes were examined and the percentage of phagocytes and average number of bacteria per phagocyte recorded. The degree of spontaneous phagocytosis occurring with each antigen is shown in table 3.

\section{RESULTS WITH THE SERUMS OF HEALTHY PERSONS}

The results observed with the serums of 9 healthy adults are shown in table 3 and summarized in table 6.

TABLE 3

Results of Phagocytosis Tests with Serums of Healthy Persons

\begin{tabular}{|c|c|c|c|c|c|c|c|c|c|c|}
\hline \multirow[b]{2}{*}{ Serum } & \multicolumn{2}{|c|}{$\begin{array}{l}\text { Strepto- } \\
\text { cocei }\end{array}$} & \multicolumn{2}{|c|}{$\begin{array}{l}\text { M. catar- } \\
\text { rhalis }\end{array}$} & \multicolumn{2}{|c|}{$\underset{\text { Cocei }}{\text { Staphylo- }}$} & \multicolumn{2}{|c|}{$\begin{array}{l}\text { Pseudodiph- } \\
\text { theria Bacillus }\end{array}$} & \multicolumn{2}{|c|}{$\begin{array}{l}\text { B. influ- } \\
\text { enzae }\end{array}$} \\
\hline & $\begin{array}{c}\text { Per- } \\
\text { cent- } \\
\text { age } \\
\text { of } \\
\text { Phago- } \\
\text { cytes }\end{array}$ & $\begin{array}{c}\text { Aver- } \\
\text { age } \\
\text { No. of } \\
\text { Bac- } \\
\text { teria } \\
\text { per } \\
\text { Phago- } \\
\text { cyte }\end{array}$ & $\begin{array}{l}\text { Per- } \\
\text { cent- } \\
\text { age } \\
\text { of } \\
\text { Phago- } \\
\text { cytes }\end{array}$ & $\begin{array}{c}\text { Aver- } \\
\text { age } \\
\text { No. of } \\
\text { Bac- } \\
\text { teria } \\
\text { per } \\
\text { Phago- } \\
\text { cyte }\end{array}$ & $\begin{array}{c}\text { Per- } \\
\text { cent- } \\
\text { age } \\
\text { of } \\
\text { Phago- } \\
\text { cytes }\end{array}$ & $\begin{array}{c}\text { Aver- } \\
\text { age } \\
\text { No. of } \\
\text { Bac- } \\
\text { teria } \\
\text { per } \\
\text { Phago- } \\
\text { cyte }\end{array}$ & $\begin{array}{l}\text { Per- } \\
\text { cent- } \\
\text { age } \\
\text { of } \\
\text { Phago- } \\
\text { cytes }\end{array}$ & $\begin{array}{l}\text { Aver- } \\
\text { age } \\
\text { No. of } \\
\text { Bac- } \\
\text { teria } \\
\text { per } \\
\text { Phago- } \\
\text { cyte }\end{array}$ & $\begin{array}{l}\text { Per- } \\
\text { cent- } \\
\text { age } \\
\text { of } \\
\text { Phago- } \\
\text { cytes }\end{array}$ & $\begin{array}{c}\text { Aver- } \\
\text { age } \\
\text { No. of } \\
\text { Bac- } \\
\text { teria } \\
\text { per } \\
\text { Phago- } \\
\text { cyte }\end{array}$ \\
\hline $\begin{array}{c}1 \\
2 \\
3 \\
4 \\
5 \\
6 \\
7 \\
8 \\
9 \\
\text { Control } \\
\text { Control }\end{array}$ & $\begin{array}{r}4 \\
4 \\
6 \\
12 \\
24 \\
12 \\
18 \\
16 \\
12 \\
8 \\
6\end{array}$ & $\begin{array}{l}0.4 \\
0.8 \\
2.0 \\
2.0 \\
2.2 \\
2.2 \\
2.0 \\
1.6 \\
1.5 \\
1.4 \\
1.2\end{array}$ & $\begin{array}{r}6 \\
10 \\
20 \\
20 \\
26 \\
26 \\
18 \\
26 \\
20 \\
6 \\
10\end{array}$ & $\begin{array}{l}4.0 \\
3.0 \\
3.0 \\
2.5 \\
1.4 \\
2.0 \\
1.8 \\
2.0 \\
2.4 \\
1.8 \\
2.0\end{array}$ & $\begin{array}{l}16 \\
36 \\
42 \\
32 \\
40 \\
44 \\
34 \\
22 \\
42 \\
12 \\
16\end{array}$ & $\begin{array}{l}4.0 \\
4.2 \\
4.0 \\
3.0 \\
3.0 \\
3.4 \\
2.4 \\
3.0 \\
4.0 \\
1.5 \\
1.4\end{array}$ & $\begin{array}{r}2 \\
12 \\
22 \\
16 \\
16 \\
12 \\
10 \\
18 \\
10 \\
4 \\
4\end{array}$ & $\begin{array}{l}2.0 \\
3.8 \\
3.0 \\
2.0 \\
1.5 \\
2.4 \\
1.6 \\
1.6 \\
1.2 \\
0.8 \\
0.6\end{array}$ & $\begin{array}{r}6 \\
6 \\
6 \\
8 \\
16 \\
10 \\
12 \\
10 \\
6 \\
8 \\
10\end{array}$ & $\begin{array}{l}2.0 \\
1.5 \\
1.2 \\
2.0 \\
1.3 \\
2.0 \\
1.1 \\
1.4 \\
2.4 \\
2.0 \\
1.8\end{array}$ \\
\hline
\end{tabular}

As shown in table 4 considerable variation in the percentage of leukocytes becoming phagocytes were found to occur; similar variations were found in the number of bacteria engulfed. For this reason an accurate analysis cannot be made, but the results interpreted by viewing the whole, in which the taking of averages aids slightly in evaluation. Much better data could have been secured had it been possible for us to secure and study the serums of persons before and at intervals during the illness with influenza. ${ }^{3}$

3 Tunnicliff (Phagocytic Experiments in Influenza, Jour. Am. Med. Assn., 1918, 71, p. 1733) reports that specific opsonins for a green-producing streptococcus isolated by Mathers, developed during the course of the influenza. A specific decrease in opsonins for this organism occurred in pneumonia fóllowing influenza, which persisted until recovery when a rise above normal occurred. No fluctuations in opsonin were observed with Bacillus infuenzae, Micrococcus catarrhalis or hemolytic streptococcus. 
With the polyvalent antigen of B. influenzae from $4-16 \%$ of leukocytes were found to engulf the bacilli, which degree of phagocytosis was quite similar to that observed spontaneously in the absence of serum. According to our results normal human serum contains none or but traces of thermostabile opsonin for the influenza bacillus.

About $60 \%$ of serums of healthy persons were found to contain slight amounts of thermostabile opsonin for the hemolytic streptococci employed in these tests, and the majority contained traces also for M. catarrhalis, Staph. aureus and pseudodiphtheria bacilli.

\section{RESULTS WITH THE SERUMS OF PERSONS SUFFERING WITH INFLUENZA}

The results of phagocytosis tests with the serums of 19 persons varying from the 3rd to the 25th day of the disease, are shown in tables 4 and 5 ; of these 19 patients, 9 were regarded clinically as having bronchopneumonia at the time the specimens of blood were taken for these tests.

As previously stated considerable variation in results was observed, but it would appear that a slight increase of thermostabile opsonin for B. influenzae occurs in the majority of persons and particularly after the first week of influenza; with the serums of persons suffering with bronchopneumonia, less phagocytosis was generally observed.

Thermostabile opsonins for hemolytic streptococci were generally increased and particularly during the first week of influenza and before the onset of bronchopneumonia; with the serums of persons suffering with pneumonia a general decrease in opsonin content wi: apparent.

The amounts of thermostabile opsonins for M. catarrhalis, Staph. aureus and pseudodiphtheria bacilli in the serums of influenza patients were practically the same as found in the serums of healthy adults.

$$
\text { RESULTS OF AGGLUTINATION TESTS }
$$

Microscopic agglutination tests were made with a number of heated serums from healthy persons; and tests with influenza serums were made with the same polyvalent bacterial antigens employed in the complement fixation tests.

In making these tests the mixtures of serum and bacterial emulsions were incubated at $55 \mathrm{C}$. on a water-bath for 2 hours and read 

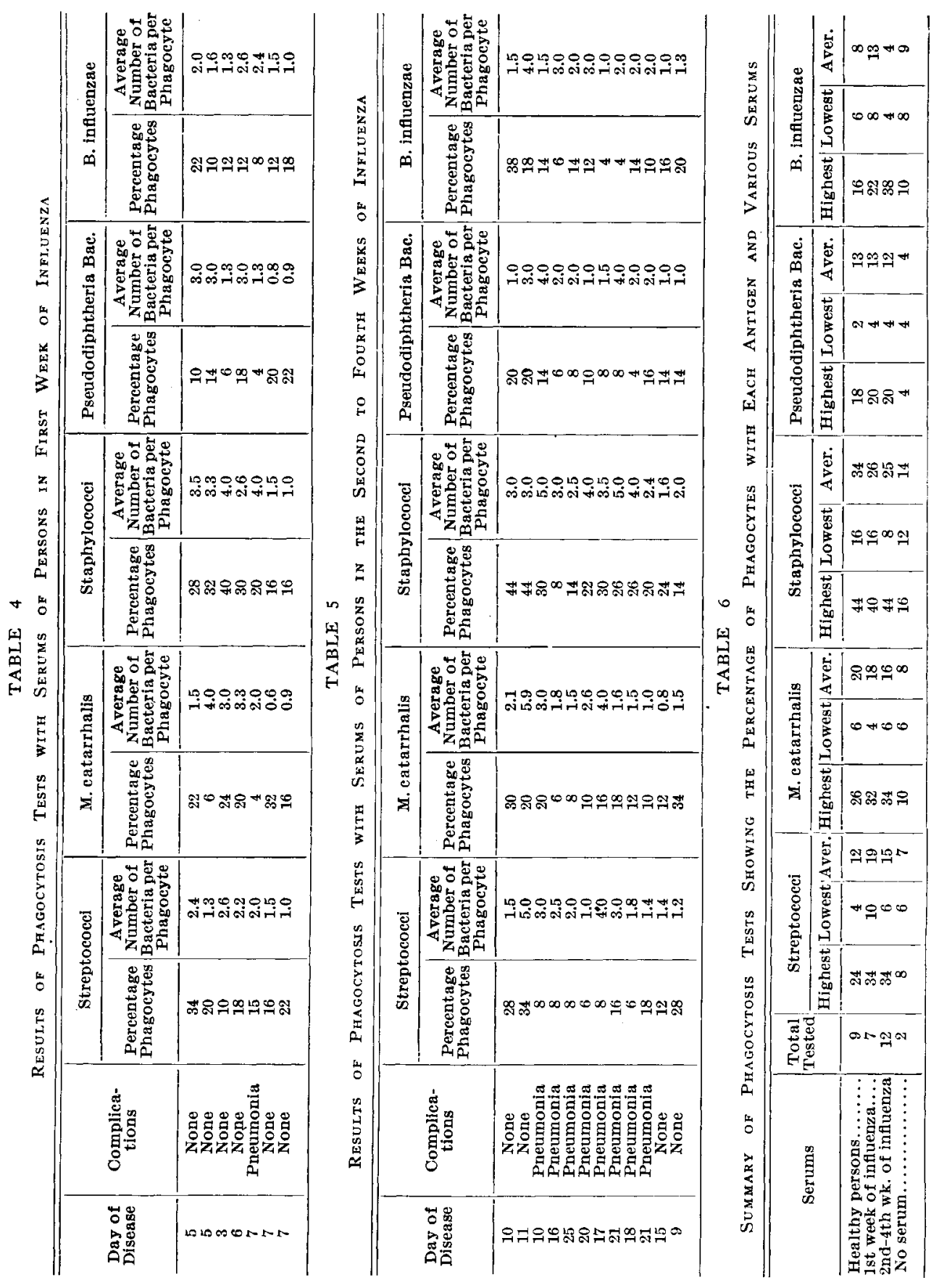

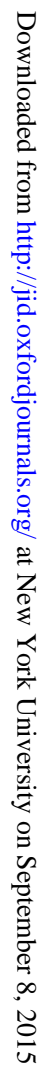


after standing in a refrigerator over night. The usual salt solution controls were included.

Microscopic tests were made also but the majority of cultures of B. influenzae, streptococci and M. catarrhalis showed sufficient spontaneous agglutination to interfere with the interpretation of these tests.

The results observed may be summarized as follows:

The heated serum of the majority of normal healthy adults did not agglutinate the polyvalent antigen of $B$. influenzae even in dilutions as low as $1: 2$; a few serums produced partial agglutination in dilution of $1: 2$ but not in higher dilutions (table 7).

Similar results with heated normal serums were observed with the polyvalent antigens of hemolytic streptococci, M. catarrhalis, Staph. aureus and pseudodiphtheria bacillus.

TABLE 7

Results of Macroscopic Agglutination tests with Polyyalent Antigen of B. INFLUENZAE

\begin{tabular}{|c|c|c|c|c|c|c|}
\hline \multirow{2}{*}{ Serum } & \multicolumn{6}{|c|}{ Final Dilutions } \\
\hline & $1: 2$ & $1: 4$ & $1: 8$ & $1: 16$ & $1: 32$ & $1: 64$ \\
\hline 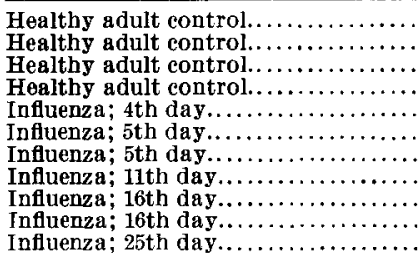 & $\begin{array}{l}- \\
\pm \\
\pm \\
\pm \\
\pm \\
\pm \\
+ \\
+ \\
+ \\
+ \\
+\end{array}$ & $\begin{array}{l}\overline{-} \\
\bar{z} \\
= \\
= \\
\overline{+} \\
+ \\
+ \\
+\end{array}$ & $\begin{array}{l}- \\
= \\
= \\
= \\
= \\
\overline{+} \\
+ \\
+\end{array}$ & $\begin{array}{l}\bar{z} \\
= \\
= \\
= \\
\bar{z} \\
\pm\end{array}$ & $\begin{array}{l}\bar{z} \\
\bar{z} \\
\bar{z} \\
\overline{ \pm}\end{array}$ & $\begin{array}{l}\bar{z} \\
\bar{z} \\
\bar{z} \\
\bar{z}\end{array}$ \\
\hline
\end{tabular}

Appreciable amounts of agglutinin for B. influenzae was found in about $30 \%$ of serums from persons suffering with influenza after the 1st week of the disease; as a general rule the limits of agglutination were found in dilutions $1: 8$ to $1: 32$ but with the serums of 2 persons who had suffered with a bronchopneuomnia agglutination occurred in dilutions as high as $1: 64$.

The serums of 2 persons suffering with bronchopneumonia tested on the 15th and 18th days of illness, respectively, agglutinated the polyvalent antigen of hemolytic streptococci in dilutions up to $1: 4$, but tests with the remaining serums yielded negative results.

All tests with polyvalent antigens of M. catarrhalis, Staph. aureus and pseudodiphtheria bacillus yielded negative results. 
The general results indicate that antibodies and particularly the complement fixing body, are developed in the serums of most influenza patients for B. influenzae and to a lesser extent for hemolytic streptococci and M. catarrhalis; similar studies were not made with pneumococci. These results, however, cannot be interpreted as an indication that the bacillus of influenza is the primary or chief cause of influenza inasmuch as this bacillus very probably possesses in the majority of cases sufficient pathogenicity to stimulate antibody production as an organism of secondary infection; similar studies with the streptococci of scarlet fever and the micrococci of acute anterior poliomyelitis indicate that what are very probably organisms of secondary infection, may stimulate specific antibody production.

In general, the results of this investigation indicate on the basis of antibody production by the various organisms studied, that the bacillus of influenza produces most antibody during the course of the disease, and if this bacillus is not the actual or primary cause of the infection it is at least the chief organism of secondary infection, with streptococci ranking second in antibody production and importance.

\section{SUMMARY}

Complement fixation, phagocytosis and agglutination tests were made with the serums of healthy adults who had never had influenza and with the serums of persons in varying stages of influenza and bronchopneumonia, with polyvalent antigens of B. influenzae, hemolytic streptococci, M. catarrhalis, Staph. aureus and pseudodiphtheria bacillus.

The serums of normal healthy adults did not fix complement with the polyvalent antigen of $B$. influenzae and the majority were free of thermostabile opsonin and agglutinin for these bacilli.

The serums of from $45-50 \%$ of persons suffering with influenza yielded complement fixation with the polyvalent antigen of $B$. influenzae.

A slight increase of thermostabile opsonin for B. influenzae was found with the majority of serums and particularly after the 1st week of the disease; during bronchopneumonia a decrease in opsonic activity of the serum was generally apparent. 
Slight amounts of agglutinin for a polyvalent antigen of B. influenzae was found in about $30 \%$ of serums of persons suffering with influenza after the 1st week of the disease.

The serums of normal healthy adults yielded no complement fixation with polyvalent antigen of hemolytic streptococei; positive reactions were observed with about $38 \%$ of serums from persons with influenza.

A slight increase of thermostabile opsonin for hemolytic streptococci generally occurred during the 1st week of influenza with a decrease during the period of pneumonia; an increase of agglutinin was not apparent.

Complement fixation was not obtained with the serums of normal healthy adults and a polyvalent antigen of M. catarrhalis; about 38\% of the serums of persons suffering with influenza yielded positive reactions. As a general rule, no increase of thermostabile opsonin or agglutinin for this antigen was detected in the serums of persons with influenza.

Complement fixation tests with the serums of normal healthy adults yielded negative reactions with the polyvalent antigens of Staph. aureus and pseudodiphtheria bacillus; the serums of persons suffering with influenza likewise generally yielded negative reactions and did not show appreciable increase in thermostabile opsonin and agglutinin for these antigens.

The general results of this investigation have shown that in Philadelphia, as a result of influenza, most antibody production occurred for the $B$. influenzae indicating that this bacillus very probably exerted the most important rôle in the disease as an organism of secondary infection if not the actual or primary etiologic agent; streptococci and M. catarrhalis were also sufficiently pathogenic to produce appreciable amounts of antibodies in the serums of many persons suffering or convalescent from influenza. 